\title{
Improving the effectiveness of treatment of chronic generalized catarrhal gingivitis in cadets of the Ufa Law Institute of the Ministry of Internal Affairs of the Russian Federation who are under psychoemotional stress
}

\author{
Olesya Sitdikova ${ }^{1 *}$, Milyausha Kabirova $^{1}$, Larisa Gerasimova ${ }^{1}$ and Lida Sitdikova ${ }^{1}$ \\ ${ }^{1}$ Federal State Budgetary Educational Institution of Higher Education "Bashkir State Medical \\ University" of the Ministry of Health of the Russian Federation, 450000, Ufa, Russian Federation
}

\begin{abstract}
The purpose of the study was to determine the influence of the psychoemotional stress level on the development of chronic generalized catarrhal gingivitis, to suggest a treatment regimen using a complex of glycine and burnet (Sanguisorba) phytocomposition. Materials and methods. In a clinical study based on the dental office of the medical unit No. 1 of the medical and sanitary unit of the Ministry of Internal Affairs of the Russian Federation in the Republic of Bashkortostan (city of Ufa) involved 77 patients aged from 18 to 25 years with chronic generalized catarrhal gingivitis. Results. The use of the proposed complex of glycine and burnet phytocomposition in gel form is convenient to use, since it allows to increase the exposure time on the oral mucosa and provides an optimal concentration of drugs to achieve the fastest therapeutic effect. Conclusion. The study proved the role of stress factors in the genesis of periodontal injuries. The immunosuppressive effect of stress stimulations directly affects the hygienic status of the oral cavity. This medicinal composition of glycine and burnet phytocomposition has demonstrated effectiveness and ease of use. It requires further introduction as an additional tool in the treatment of chronic generalized catarrhal gingivitis against the background of psychoemotional stress.
\end{abstract}

\section{Introduction}

Periodontal diseases of inflammatory origin are a serious problem. The complexity of conservative treatment and the variety of causes of periodontal diseases make it necessary to study again and again the factors that affect the etiology and pathogenesis of this disease [1]. Major importance in the development and progression of inflammatory periodontal diseases is assigned to both local and general factors. In the scientific literature, special attention is paid to professional factors closely related to stress, which have a significant impact on the course of the inflammatory process of periodontal tissues [2,3]. Our attention is drawn to the professional impact on the health of specialists whose activities are associated with an active and emotionally negative work schedule. Employees of internal affairs agencies are subjected to professional stress, who are forced to perform their official duties in a strictly limited time

*Corresponding author: jdreams@ya.ru 
frame in a tense socio-economic situation in the country [4-6]. A busy work schedule negatively affects the health of employees of internal affairs agencies, so various diseases are common among them. One of the most frequent manifestations of occupational hazards, in particular occupational stress, is periodontal disease [7]. There are also other factors for psychoemotional stress that are caused by social relationships among employees and weigh down the effect of the primary impact. These include: constant stress during the day, moral discomfort, refusal to provide sufficient psychological assistance, disrespectful attitude of others to their work and high demands of their superiors. Recently, the identity of an employee of the Ministry of Internal Affairs has often become the object of scientific medical research. It is very important to obtain reliable information about the role of external and internal, that is, personal, factors that enhance or reduce the impact of occupational hazards on their health. This knowledge helps to provide law enforcement officers with well-chosen specialized medical care. Professional rehabilitation of employees of the Ministry of Internal Affairs is a very important and necessary condition for maintaining their health and fulfillment of the important state activities within the terms set for them [8,9]. Cadets of military universities are also of particular interest. The stage of entering a higher military educational institution can be considered as entering an independent life. At this point in the psychology of a first-year student, changes occur that affect his consciousness, associated with parting with the school team, leaving the family, being unprepared for University, being restricted in freedom, and following the orders of commanders and superiors. Exactly during this period, the cadet begins to experience a strong psychological phenomenon - adaptation to study in a military educational institution. The most difficult for cadets is the first year, since it is associated with entering a different environment, that is, with adapting to learning. The old structure of behavior changes, new habits appear. The contradiction between the volume and complexity of the educational material and the lack of desire and ability to study at the university are distinctive features of first-year cadets. Students should not only learn to listen to and record lectures, but also independently study and take notes on literature, prepare for practical and seminar classes. Such qualities as independence, responsibility, ability to correctly allocate time, and desire to learn come to the fore. It is very important to understand the difference between studying in a civil and military higher educational institution. Studying at a military higher educational institution has the following features: specificity of knowledge, skills, abilities and qualities that must be formed in soldiers, due to their focus on preventing aggression and, if necessary, suppressing, destroying the enemy [10]; military affairs study for military personnel is a duty [11,12]; training of military personnel is carried out inseparably from the performance of official duties, in conditions of constant combat readiness [12]. Very often, cadets have an unbroken chain of changing activities: training sessions - entry on duty - carrying the duty - change of duty - training sessions, which leaves them little time to prepare for classes. At the same time, individual and collective forms of training are used [13]. Training of military personnel has a pronounced practical orientation [14], in this regard, the training department plans trips to field training centers for cadets. Mastering military skills is carried out using real military equipment and weapons "14". The training process is carried out within the framework of the statutory organization, directed by the commander-in-chief, and is regulated in detail and strictly by the requirements of the governing documents, which define a principled approach to the content, organization and methodology of military training and education [13]. These features of training cause the cadet a crisis associated with the difficulty of adapting to new requirements without assistance. Cadets have a feeling of anxiety, lack of confidence in their abilities, doubt about the correctness of their choice of profession. As observations show, it is in the first year that a greater number of cadets are expelled. The emergence of a crisis situation is associated with the process of adaptation. Chronic generalized catarrhal gingivitis is most common among 
dental diseases in young people [17]. A large number of studies is devoted to the study of the etiology and pathogenesis of this disease.

\subsection{Purpose of research}

To determine the influence of the level of psychoemotional stress on the development of chronic generalized catarrhal gingivitis in cadets of the Ufa Law Institute, to propose a treatment regimen using the drug form developed by us in gel form based on a complex of glycine and great burnet phytocomposition (Sanguisorba officinalis)

\section{Materials and methods of research}

We conducted a dental examination of 77 persons aged 18 to 25 years on the basis of the dental office of the medical unit No. 1 of the medical and sanitary unit of the Ministry of Internal Affairs of the Russian Federation in the Republic of Bashkortostan (city of Ufa). All patients were male. The study was conducted with the permission of the head of the Institute, Colonel A.S. Khanakhmedov, as well as with the informed consent of the cadets themselves, revealing the procedure for manipulations with possible side effects. All cadets signed a protocol of informed consent to participate in the study.

The selection criteria were the following: consent to participate in the study, "chronic generalized catarrhal gingivitis" diagnosis (K05.10 Chronic gingivitis. Simple marginal"), age from 18 to 25 years.

Non-inclusion criteria: age younger than 18 and older than 25 years; partial secondary edentulism; previous orthodontic treatment; presence of additional factors of plaque retention (fillings with an overhanging edge in the neck area, artificial crowns); use of cytostatics, immunosuppressants and corticosteroids (systemically or locally) over the past six months; diseases of the oral mucosa; signs of acute infectious disease; hypersensitivity to the drug components.

Exclusion criteria: refusal to repeat clinical examinations, non-compliance with the rules of the oral cavity hygiene, occurrence of undesirable effects that require drug withdrawal.

Prior to the treatment, patients underwent a comprehensive examination, which allowed them to obtain initial information in a form that is convenient for further statistical processing. Dental status was formalized using a set of dental indexes. Before the start of the examination, each patient was taken a panoramic image on the ORTHOPHOS SL 2D device (Germany), which was repeated one year later. Periodontal pockets were measured with a graduated probe. A dental formula was used recommended by the World Health Organization to preserve information about the condition of teeth and periodontium. Examination of patients was carried out according to the plan, which includes a standard set of interview, inspection, palpation and drafting occlusiogram. During the collection of the disease history, attention was focused on the peculiarities of the course of the disease, whether there are harmful habits, medicinal or other allergic reactions. During the examination, the depth of the oral cavity atrium, the state of the oral mucosa, the location of the tongue and lips frenulum were evaluated, the height level of the alveolar processes was noted on the orthopantomogram. Then they described the condition of the tongue surface and the hard and soft palate. All of the above, along with the condition of the teeth, was recorded in individual patient records. The Green-Vermilion hygiene index (HI), the Russell periodontal index (PI), and the Muhlemann bleeding index (BI) were used to determine an objective assessment of the clinical condition of periodontal tissues. In parallel with the clinical dental examination, psychological testing of patients was conducted to detect symptoms of depression under the Beck scale (Beck Depression Inventory, 1961).

All the studied patients received conservative treatment for gingivitis. They were trained in individual oral hygiene using disposable hygiene products on a dentition artificial model. 
Individual hygiene products - a toothbrush, paste, and an irrigator, were selected. At the next stage of the study, the patients of each of the formed groups were divided into 3 more groups. A complete sanitation of the oral cavity was performed in each patient. Patients of all groups were given professional oral hygiene:

- elimination of all dental deposits (supra-gingival) with a multifunctional ultrasonic autonomous scaler "Varios VA970 LUX" (Japan);

- closed curettage of periodontal pockets using Gracie curette "Hu-Friedy" (Germany) (if necessary).

Selective grinding of teeth was conducted according to occluziongram to eliminate traumatic occlusion. Patients of the first group were treated with medication in the following way: the mucous surface of the gums was treated with a $0.2 \%$ solution of chlorhexidine bigluconate, applications of a complex of Metrogil-gel - Denta with trichopol were applied to the gums and in the interdental spaces for 10 days.

Patients of the second group received applications periodontocide to the gum mucosa, to prolong the action of the gel, a medicinal film of Deplain-denta was applied to the gum. In addition to applications, patients were prescribed a tablet of Askorutin 1 tablet 2 times a day (for 14 days). In addition to traditional therapy, patients of the third group received to the gum mucosa applications of a specially developed gel with the addition of glycine and burnet phytocomposition, which was introduced into the oral cavity in a soft disposable dental mouthguard for five minutes for 10 days. Garden burnet Sanguisorba officinalis is a perennial herb belonging to the Rosaceae family. The rootstalks contain tanning agents (up to $23 \%$ ), starch (up to 30\%), essential oil, saponins, coloring agents [16], gallic and ellagic acid. Roots contain 16-17\%, callus - up to $23 \%$ of tanning agents of the pyrogallic group; leaves ascorbic acid (up to $0.92 \%$ ). Roots and rootstalks also contain macronutrients $(\mathrm{mg} / \mathrm{g}$ ): potassium - 5.8, calcium - 23.1, magnesium - 2.9, iron - 0.4; trace elements $(\mathrm{mcg} / \mathrm{g})$ : manganese -0.47 , copper -0.59 , zinc -1.02 , cobalt -0.04 , chromium -0.03 , aluminum -0.31 , barium -5.71 , vanadium -0.12 , selenium -1.39 , nickel -1.15 , strontium -6.14 , lead -0.06 , iodine -0.1 , borium -2.0 . Roots and rootstalks can concentrate zinc, nickel, selenium, and especially barium and strontium [15]. The value of the chemical composition of garden burnet for the oral mucosa: natural antiseptic, it relieves inflammation, has a bactericidal property, prevents the development of harmful bacteria, normalizes metabolism, has a calming effect, relieves pain, increases immunity, has a hemostatic, healing effect. Therefore, the burnet was chosen as the main active substance in our medication.

Treatment and distribution of patients into groups was carried out by stratified randomization. This method allows to create groups that are homogeneous in some way. In this case, it was necessary that each group included patients with different levels of depression and chronic generalized catarrhal gingivitis. In other words, it was necessary to exclude a situation where one group would have patients with a predominantly mild level of depression, and the other - patients with a moderate level, since this could affect the average values of the studied indicators. To do this, before randomization a stratification was conducted: patients were divided into groups (strata) depending on age, level of depression, and then in each group were randomized in a ratio of 1:1:1 (every first patient in the stratum were included in group 1 (treated with $0.2 \%$ chlorhexidine solution, applications of a compound with Metrogyl-gel-denta with trichopol), the second one - to group 2 (application of parodontotsid to gingival mucosa, for gel effect renewal drug film Deplen-denta was applied on the gums, Ascorutin pills were prescribed), third one - to group 3 (application of specially developed gel to gingival mucosa with the addition of glycine and burnet phytocomposition).

Examination of patients within the framework of randomized study was carried out before treatment, as well as 3, 6, 12 months after the start of treatment. 
The results of clinical data were subjected to variational statistical processing using the Student-Fisher criterion with definitions of the arithmetical average (M), its error (m), criterion $(\mathrm{t})$, and probability of the null hypothesis $(\mathrm{Pt})$. The results were considered reliable if the percentage of acceptable error was no more than $5 \%$, i.e. $\mathrm{p}<0.05$. All calculations were performed using the computer program MS Office 2007, SPSS 11.5.

\section{Results of the study and their discussion}

At the first stage of the study, all cadets of the ULI of the Ministry of Internal Affairs of the Russian Federation passed a general clinical examination. The first group is the 1st year cadets who are experiencing a high stress load in the first year of training - their activity is characterized by frequent psychological overloads and the need to regularly combine studies, entering on duty, drill practice, physical training, household work, cleaning the territory, regardless of weather conditions. The schedule of the educational process of persons belonging to the first group is irregular, characterized by the absence of days off and living in the military barracks. The second group consisted of 4th-year cadets who have a low stress load, who have a normalized 8-hour school day, they do not go to duty, to fatigue duty, physical training, and live in the city, in civilian conditions. After the examination, all the patients participating in the study were distributed by age, levels of psychoemotional stress loads. Thus, the total number of patients with chronic generalized catarrhal gingivitis (CGCG) was 77. Participants were divided into age groups: from 18 to 20, from 21 to 22, from 23 to 25 (table 1 ).

Table 1. Separation of patients with chronic generalized catarrhal gingivitis (CGCG)by age and stress loads.

\begin{tabular}{|c|c|c|}
\hline Age group, years & Moderate depression & Mild depression \\
\cline { 2 - 3 } & CGCG & CGCG \\
\hline $18-20$ & 28 & 19 \\
\hline $21-22$ & 22 & 1 \\
\hline $23-25$ & 4 & 23 \\
\hline Total & 54 & 3 \\
\hline
\end{tabular}

Complaints that patients presented with chronic generalized catarrhal gingivitis (CGCG): bleeding when brushing teeth, soreness, bad breath, burning, redness, cyanosis of the gums, loosening of the gums, profuse salivation. In an objective study, all patients had microbial plaque, supragingival solid and soft dental deposits, the maximum amount of which was in the frontal segment on the lower teeth and on the buccal surface of the maxillar molars. In chronic generalized catarrhal gingivitis (CGCG), the alveolar gum mucosa was hyperemic, moderately edematous, and bleeding was observed during probing. The analysis of orthopantomograms did not show any changes in the partitions between the teeth, and there were no foci of destruction.

Based on the results of the examination of the treatment performed:

1. In patients of the first group, there is a noticeable induration of the gingival margin, no unpleasant smell from the mouth, bleeding of the gingival papillae during probing, no soreness;

2. In patients of the second group, there was a significant induration of the gingival margin, the color of the gum mucosa is pale pink, and there is no soreness.

In one year after the end of treatment according to orthopantomograms, there is no destruction of bone tissue, and the height of the alveolar partitions is preserved. In patients of the third group, the treatment time was significantly reduced compared to the first and second group of patients. There was a clinical recovery of the oral mucosa, the gums tightly 
covered the teeth in the neck area, the process was stabilized, the gums had a physiological color, no soreness, edema, cyanosis (tables 2, 3).

Table 2. Dynamics of the periodontal index (PI) in patients with CGCG under low stress loads.

\begin{tabular}{|c|c|c|c|c|}
\hline \multirow{2}{*}{ Age group } & \multicolumn{4}{|c|}{ PI, c.u. } \\
\cline { 2 - 5 } & $\begin{array}{c}\text { Before } \\
\text { treatment }\end{array}$ & $\begin{array}{c}\text { After } \\
3 \text { months }\end{array}$ & $\begin{array}{c}\text { After } \\
6 \text { months }\end{array}$ & $\begin{array}{c}\text { After } \\
12 \text { months }\end{array}$ \\
\hline I & $3.75 \pm 0.3^{*}$ & $1.38 \pm 0.4^{*}$ & $1.45 \pm 0.4^{*}$ & $2.4 \pm 0.4^{*}$ \\
\hline II & $3.75 \pm 0.3^{*}$ & $1.55 \pm 0.3^{*}$ & $1.78 \pm 0.4^{*}$ & $1.9 \pm 0.3^{*}$ \\
\hline III & $3.75 \pm 0.3^{*}$ & $1.38 \pm 0.3^{*}$ & $1.7 \pm 0.4^{*}$ & $1.8 \pm 0.4^{*}$ \\
\hline
\end{tabular}

Note: ${ }^{*}-\mathrm{p}<0.05$; $\mathrm{p}$ is calculated in relation to indicators: «before treatment»

Table 3. Dynamics of the periodontal index (PI) in patients with CGCG under high stress loads.

\begin{tabular}{|c|c|c|c|c|}
\hline \multirow{2}{*}{ Age group } & \multicolumn{4}{|c|}{ PI, c.u. } \\
\cline { 2 - 5 } & $\begin{array}{c}\text { before } \\
\text { treatment }\end{array}$ & after 3 months & after 6 months & after 12 months \\
\hline I & $3.75 \pm 0.3^{*}$ & $1.25 \pm 0.3^{*}$ & $1.7 \pm 0.4^{*}$ & $1.85 \pm 0.4^{*}$ \\
\hline II & $3.75 \pm 0.3^{*}$ & $1.65 \pm 0.4^{*}$ & $2.21 \pm 0.4^{*}$ & $1.95 \pm 0.4^{*}$ \\
\hline III & $3.75 \pm 0.3^{*}$ & $1.5 \pm 0.3^{*}$ & $2.1 \pm 0.4^{*}$ & $2.5 \pm 0.3^{*}$ \\
\hline
\end{tabular}

Note: $*-\mathrm{p}<0.05 ; \mathrm{p}$ is calculated in relation to indicators: «before treatment».

\section{Conclusion}

As a result of ongoing research in the etiology of periodontal disease the role of stress factors was confirmed on the example of cadets of ULI of the MIA RF. A high incidence of chronic generalized catarrhal gingivitis (CGCG) was found in all age groups of the studied cadets. The immunosuppressive effect of stress stimultions affects the hygienic status of the oral cavity. People who are under psychoemotional stress have difficulties in complying with the basic rules of maintaining their health - there is no time for rest, full sleep, balanced nutrition, and the possibility of receiving timely prevention is reduced to zero. In this regard, it is very important to develop tools for the prevention and treatment of diseases that are effective in a short time of their use. The scheme of treatment of chronic generalized catarrhal gingivitis developed by us with the use of a complex of glycine and burnet phyto-complex containing a high concentration of vitamin $\mathrm{C}$, sterols, and essential oils can be recommended as a supplement to traditional anti-inflammatory therapy. During the study 12 months after the treatment of CGCG, with the proposed treatment scheme PI in group III was significantly higher at high stress loads PI - $2.5 \pm 0.3^{*}$. This treatment increases the effectiveness of conservative therapy for chronic generalized catarrhal gingivitis against the background of immunosuppressive effect caused by psychoemotional stress. The use of the gel developed by us from glycine and burnet is quite convenient to use, as it allows to significantly increase the time of gel exposure on the mucosa and provide an optimal concentration of antiinflammatory substances for the fastest possible therapeutic effect.

Our medicinal component demonstrates its effectiveness and ease of use, the drug requires further introduction as an additional treatment for chronic generalized catarrhal gingivitis, including in patients with high stress loads. 


\section{References}

1. L. M. Tsepov, A. I. Nikolaev, M. M. Nesterova, D. A. Nakonechny, Nanotechnologies in dentistry: proceedings of the conference dedicated to the 60th anniversary of the TSMA. city of Tver, The problem of etiology of inflammatory generalized periodontal diseases. Modern dentistry - effectiveness of prevention and treatment, 310-319 (2014)

2. L. M. Tarasenko, T. A. Petrushanko, city of Poltava, Stress and parodontium, 192 (1999)

3. O. V. Kononova, Bulletin of problems of biology and medicine, 1 (4), 36-41 (2016)

4. I. M. Makeeva, V. S. Bulgakov, I. A. Nikolskaya, Health and education in the XXI century, 1, 140-141 (2008)

5. P. A. Korchemny, Psychopedagogics in law enforcement agencies, 1 (56), 78-80 (2014)

6. V. A. Taburtsa, Scientific and methodological electronic journal "Concept", 13, 3126$3130(2015)$

7. N. A. Korenevskaya, I. V. Gorodetskaya, Bulletin of the Vitebsk State Medical University, 3, 155-163 (2015)

8. A. R. Aliyev, Bulletin of problems of biology and medicine, 1, 341-344 (2017)

9. V. De Iuliis, S. Ursi, L. M. Di Tommaso, M. Caruso, A. Marino, S. Ercole, S. Caputi, B. Sinjari, F. Festa, M. Macri, S. Martinotti, G. Vitullo, E.J. Toniato, Biol. Regul. Homeost, 4, 1209-1215 (2016)

10. O. Yu. Efremova, city of Saint Petersburg, Military pedagogy: textbook for HEI, 640 (2014)

11. D. Ya. Raigorodsky, Methods and tests: textbook. Manual, 672 (2001)

12. Order of the Minister of defense of the Russian Federation No. 505 dated 07.09.2015 "On the procedure for conducting military medical expertise in the Armed Forces of the Russian Federation", 324 (2015)

13. Resolution of the Government of the Russian Federation No. 565 dated 04.07.2015 "On approval of the Regulations on military medical examination" 320 (2015)

14. Order of the Ministry of Internal Affairs of the Russian Federation No. 190 dated April 2, 2018 "On health requirements for citizens entering the service of the internal affairs bodies of the Russian Federation" 64-67 (2018)

15. T. A. Goncharova, MSP House, Encyclopedia of medicinal plants, 5-7 (1997)

16. I. A. Gubanov, I. L. Krylova, V. L. Tikhonova, Thought, Wild useful plants of the USSR, 176-177 (1976)

17. V. N. Kulygina, A. M. Mohammad, Taurian Medical and Biological Bulletin, 1, 73-76 (2014) 